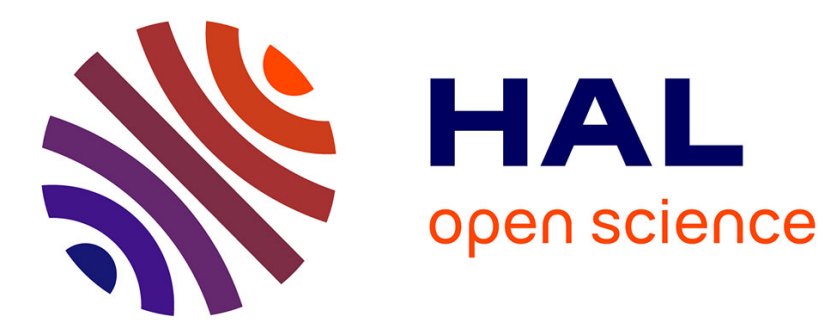

\title{
Characterization of functionalized coatings prepared from pulsed plasma polymerization
}

Marisol Ji, Andrea Jagodar, Eva Kovacevic, Lazhar Benyahia, Fabienne Poncin-Epaillard

\section{- To cite this version:}

Marisol Ji, Andrea Jagodar, Eva Kovacevic, Lazhar Benyahia, Fabienne Poncin-Epaillard. Characterization of functionalized coatings prepared from pulsed plasma polymerization. Materials Chemistry and Physics, 2021, 267, pp.124621. 10.1016/j.matchemphys.2021.124621 . hal-03367427

\section{HAL Id: hal-03367427 \\ https://hal.science/hal-03367427}

Submitted on 6 Oct 2021

HAL is a multi-disciplinary open access archive for the deposit and dissemination of scientific research documents, whether they are published or not. The documents may come from teaching and research institutions in France or abroad, or from public or private research centers.
L'archive ouverte pluridisciplinaire HAL, est destinée au dépôt et à la diffusion de documents scientifiques de niveau recherche, publiés ou non, émanant des établissements d'enseignement et de recherche français ou étrangers, des laboratoires publics ou privés. 


\title{
Characterization of functionalized coatings prepared from pulsed plasma polymerization
}

Marisol Ji ${ }^{1)}$, Andrea Jagodar ${ }^{2)}$, Eva Kovacevic ${ }^{2)}$, Lazhar Benyahia ${ }^{1)}$, Fabienne Poncin-Epaillard ${ }^{1 *}$ )

1) Institut des Molécules et Matériaux du Mans, Le Mans Université - CNRS n6283, Avenue Olivier Messiaen, 72085 Le Mans, France

2) Gremi, CNRS, Université d'Orléans, 14 rue d'Issoudun, 45067 Orléans, France

*) Corresponding author, Fabienne.poncin-epaillard@univ-lemans.fr

Keywords: plasma polymerization, acetylene, acrylic acid, maleic anhydride, FTIR, XPS and NEXAFS spectroscopies.

\begin{abstract}
:
Material assembly based on elastomer part and metallic substrate has been widely used in many industrial sectors. However, the adhesion between the two materials requests specific processes and adhesives. Plasma technology is an interesting way to prepare the assembly since the plasma polymer layers used for the adhesive joint can bear different reactive chemical functions toward the elastomer. Three different plasma coatings are synthesized from acetylene, acrylic acid, and maleic anhydride plasma because of their respective chemical functions able to open the carbon-carbon double bond of the elastomer (rubber, fluoroelastomer). For such a purpose, finetuning of plasma parameters was essential to preserve the precursor chemistry and to avoid any degradation. Pulsed plasma discharge was selected, plasma parameters defined thanks to the design of experiment. The different plasma polymers were characterized by FTIR, XPS and NEXAFS spectroscopies and surface energy measurement.
\end{abstract}

\section{Introduction}

The bonding of an elastomer to metallic substrates has been a process widely used since the beginning of the 20th century in many industrial sectors (automotive, aeronautics, aerospace, sports and leisure, etc.). Such a bonding is often finalized during the vulcanization of the elastomer at 
specific temperature and pressure. Currently, the adhesion of complex geometric assemblies is carried out by manual and repetitive application processes of one or more adhesive layers so-called primary, secondary layers which are organic or water-based liquid phases containing highly toxic products [1]. Therefore, the reliability of good mechanical strength is difficult to ensure due to an inhomogeneous adhesive bond which, moreover, is obtained under not so eco-friendly conditions. The adhesion between two materials is based on different types of mechanisms. Two of them, besides the wettability criterion, are prevalent during the vulcanization bonding, i.e. the chemical and the interpenetration (interdiffusion) mechanisms. The former deals with the reactivity of different chemical groups reacting together and forming new covalent bonds between the substrate and the elastomer while the latter highlights the polymeric chain mobility and reptation inducing an interphase layer with an intermediary composition.

Layers issued from the plasma polymerization of various organic precursors [2-5] could be an alternative solution to the toxic liquid phases. Indeed, varying the plasma chemistry and physics by tuning the different operating parameters allows to vary and to control the plasma deposit composition and thickness. On one side, since most of the elastomers are polydiene, pulsed plasma deposits ( $\mathrm{pp}$ ) bearing the precursor functions, either carbon-carbon double bonds, acid or anhydride functions are in favor of the chemical adhesion thanks to the creation of the corresponding links. On the other side, increasing the thickness of linear plasma polymers, with longer duration and pulsed wave, respectively, should enhance the interpenetration of both polymers. Acetylene (Ac), acrylic acid (AA) and maleic anhydride (MA) are representative of the functional groups that should be incorporated in the plasma adhesive bond.

A large part of the literature on thin film processes is dealing with the preparation of hydrocarbon polymers and hydrogenated amorphous carbon combining several attractive properties such as high hardness, low friction coefficient, chemical inertness, dielectric strength and biocompatibility... The plasma phase is commonly composed of various saturated or unsaturated hydrocarbons. In order to obtain a cross-linked network, sources with ion energy above $50 \mathrm{eV}$ were developed. Only few papers describe the plasma processes in milder conditions such as the pulse discharge [6-11]. The proposed mechanism of pp-Ac growth in pulsed plasma is related to the addition polymerization occurring exclusively during the off-period [12,13]. Nevertheless, asymmetric bipolar pulsed discharges operating between 50 and $350 \mathrm{kHz}$ appear to be an effective route for the DLC-like layer whose hydrogen content and sp3/sp2 bonding ratio depend on the 
precursor structure and the discharge power. At low discharge power, a sp3-rich plasma polymer with high hydrogen content is layered while at high energy level, sp2-rich hard carbon coating is formed with a low hydrogen concentration (less than $20 \%$ ) [10]. This issue allows to reduce the film internal stress due to a decrease of the substrate heating by ion bombardment and more important adatoms relaxation leading to the creation of a hard/soft multilayer [11].

Pulsed discharges have been also studied with other organic precursors for further increase of their structure retention. Another consequence of that process is also to reduce surface temperature during the deposition and the film ageing thanks to a lower density of trapped radicals. Indeed, carboxyl retention of acrylic acid is increasing with extinction time $\left(t_{\text {off }}\right)$ and decreasing with time averaged power; this was related to radical chemistry in the plasma [14-18]. Voronin et al. [18] noticed, thanks to the coupled mass spectrometry, that the monomer retention reached its maximum value of $66 \%$ for $t_{\text {off }}$ exceeding $5 \mathrm{~ms}$ while the deposition rate depends more strongly on the rate of gas flow. This retention behavior is explained by the surface grafting and the chain growth which are primarily occurring during the duty off phase [16]. This is associated with a cold but still relatively dense plasma compared to that one during the ignition phase, with very low ion energy and flux [17-19].

The maleic anhydride is of particular interest for the preparation of thin films because of the double bond and the reactive anhydride group. Compared to poly(acrylic acid), polymeric surfaces bearing anhydride groups are widely studied for improving interfacial bonding [20]. However, the anhydride group is easily degraded and the deposit may contain mostly dissociation products rather than the desired function. Therefore, the development of pulsed plasma polymerization allows to control the chemical composition of thin film. As shown with acrylic acid, the lower the discharge power is, the greater the concentration of anhydride group is [20-24]. Under pulsed plasma conditions, maleic anhydride plasma polymerization is initiated by radical scission of $\mathrm{C}-\mathrm{C}$ double bond which led to a chemical retention marked when decreasing the duty cycle. During the ignition period, the precursor degradation under ion or electron impact is also accompanied by cross-linking [22,24].

These precursors - Ac, AA and MA - were pulsed plasma polymerized for different operating plasma parameters in order to prepare different layers bearing the highest density of surface functions and with variable thickness. Their respective chemical composition is characterized by FTIR, XPS and NEXAFS spectroscopies. 


\section{Materials and methods}

\subsection{Plasma deposition and materials}

The organic precursors used without any further purification are: gaseous acetylene (AirLiquid) and liquid acrylic acid (Sigma-Aldrich) which is filled in a quartz tube connected to the chamber and vaporized thanks to the low pressure. The used solid maleic anhydride (SigmaAldrich) is filled in the quartz tube heating at $52{ }^{\circ} \mathrm{C}$ and vaporized in gas line heated at $75 \mathrm{C}^{\circ}$. The chosen elastomers are poly(acrylonitrile butadiene) rubber (NBR), fluoroelastomer (FKM) respectively provided respectively by Safran and EFJM societies.

Plasma polymerization was performed in a capacitive radio-frequency (RF, $13.56 \mathrm{MHz})$ plasma reactor. The low pressure is maintained using to a turbomolecular pump (Alcatel ATP-80) coupled with a primary rotary pump. Typical residual pressures are maintained between $10^{-5}$ and $10^{-4}$ mbar, while the working pressure is kept around $10^{-2}$ mbar and measure by a wide range capacitive-penning pressure gauge (Alcatel ACC 1009). The glow discharge is injected between two parallel electrodes separated by a fixed distance of $12 \mathrm{~cm}$, and powered with a Caesar RF generator (Advanced Energy), with powers ranging from 5 to $100 \mathrm{~W}$. Reflected power was kept minimum using to a RF Navio matchbox (Advanced Energy). Plasma discharges were performed in the pulse wave ( $t_{\text {off }}$ from 18 to $184 \mu \mathrm{s}, t_{\text {on }}$ maintained at $17 \mu \mathrm{s}, d . c$ from 8 to 50 and $f$ from $5 \mathrm{kHz}$ to $30 \mathrm{kHz}$ ). Plasma discharges were created in the different atmospheres: acetylene whose flow rates $(Q)$ varies from 10 to $40 \mathrm{sccm}$, and vapors of pure AA or MA. For the two latter, as their flow rates are not controlled, their content in the chamber was fixed with a constant working pressure of $1.010^{-2}$ mbar.

A design of experiment (DoE) was used to evaluate the effects of the different factors according to a complete 2-level factorial design plan in order to preserve the precursor chemical functions. The high and low levels of the selected factors (time $t_{\text {off }}$, discharge power $P$, gas flow $Q$ and overall duration $t$ ) are listed in Table $\mathrm{S} 1$ in supporting information. The responses to the DoE are ratio of the area of FTIR vibration bands $\mathrm{C}=\mathrm{C} /$ aliphatic $\mathrm{C}-\mathrm{H}(\mathrm{CC} / \mathrm{CH})$ and $\mathrm{C}=\mathrm{O} / \mathrm{C}-\mathrm{H}(\mathrm{CO} / \mathrm{CH})$. These are used to calculate the effects of the factors and their interactions 2 by 2 . We will neglect the 3rd order interactions because they are unlikely. 


\subsection{Surface characterization}

FTIR spectroscopy

Chemical composition of the plasma polymers (pp-Ac, pp-AA and pp-MA) deposited on transparent $\mathrm{KBr}$ pellets was extracted from Bruker Vertex $70 \mathrm{v}$ spectrometer with $2 \mathrm{~cm}^{-1}$ resolution in the range $4000-400 \mathrm{~cm}^{-1}, 40$ scans were recorded under vacuum. The FTIR spectra were done $10 \mathrm{~min}$ after the sample deposition. Spectral data were treated with Opus software for baseline correction and $\mathrm{CO}_{2} / \mathrm{H}_{2} \mathrm{O}$ subtraction.

XPS spectroscopy

The plasma coating on $\mathrm{Si} / \mathrm{SiO}_{2}$ wafers were analyzed by X-Ray Photoelectron Spectroscopy (XPS) instrument (Kratos Axis Nova, the UK, Institut des Matériaux de Nantes, France) with the monochromatic $\mathrm{Al} \mathrm{K} \alpha$ beam at the electron emission angle of $90^{\circ}$ relative to the sample surface. The pass energies for survey spectra were $80 \mathrm{eV}$ (increment $=0.5 \mathrm{eV}$ ) and $20 \mathrm{eV}$ (increment $=0.1$ $\mathrm{eV}$ ) for high resolution. The charging effect was corrected and the background subtraction was performed. The full width at half-maximum for the Gaussian peaks was maintained as a constant value for all components around $1.4 \mathrm{eV}$ depending on the layer type. The resolution fitting accuracy was $5 \%$.

NEXAFS spectroscopy

The surface chemical bonding of plasma deposits on $\mathrm{Si} / \mathrm{SiO}_{2}$ wafers has been analyzed by means of XPS and Near Edge X-ray fine structure analysis-spectroscopy (NEXAFS) performed at the Helmholtz-Zentrum Berlin für Materialien und Energie (HZB), the electron storage ring BESSYII, at the HE-SGM beamline. NEXAFS measurements are obtained at the so-called magical angle of $55^{\circ}$ (angle between linearly polarized incident light beam and the surface) [25]. Spectra were acquired at the $\mathrm{C}$ and $\mathrm{O} \mathrm{K}$-edges, in the total and partial energy electron yield (TEY and PEY) mode. The raw spectra were normalized to the incident photon flux and corrected for the beam line 
transmission by division through a spectrum which was obtained with a sputtered Au sample [2628]. The monochromator energy scale was calibrated using the carbon K-edge $\pi^{*}$ transition of graphite, located at $285.4 \mathrm{eV}$. Spectra were normalized in units of the absorption edge plateau, considering the intensity value at energy around $330 \mathrm{eV}$ for $\mathrm{C} \mathrm{K}$-edge and $560 \mathrm{eV}$ for $\mathrm{O} \mathrm{K}$-edge [29].

Wettability and surface free energy

The wettability of the plasma layers on silica substrate and elastomers surfaces was tested by means of a goniometer with $3 \mu$ high purity water drops (MilliQWater System, resistivity 18 $\mathrm{M} \Omega . \mathrm{cm}^{-1}$ ) and diiodomethane drops (Sigma-Aldrich France, $\geq 99 \%$ ). Five measurements were run on both sides of the drop at different surface locations.

Layer thickness measurement

The thickness measurement of the different layers deposited on $\mathrm{Si} / \mathrm{SiO}_{2}$ wafer was performed by to the AFM machine (Bruker Innova). Before the deposition, the substrate was partially masked. After the plasma process, the mask was removed and the level difference corresponds to the thickness of the deposit. $50 \times 50 \mu \mathrm{m}^{2}$ areas were scanned in tapping mode at ambient air. The film thicknesses were determined using Gwyddion software.

\section{Results and discussion}

\subsection{Plasma polymerization with the chemical functionality retention}

The study of the Ac, AA and MA plasma-polymerization is here focused on the preparation of highly functionalized deposit able to enhance the chemical adhesion of elastomer. This means determining the influence of different plasma parameters on the appearance of only double C-C, and the retention of acrylic acid and anhydride functions. The pulsed plasma approach offers the possibility of controlling the surface function density by limiting the electron, ion bombardments and the precursor fragmentation [30-36]. 


\section{Design of experiment for the determination of operating parameters}

The pulsed plasma polymerization was characterized using to the DoE [33,37-39] with selected parameters as the discharge power during the pulse $(P)$, the gas flow $(Q)$, the time $\left(t_{\text {off }}\right)$ while $t_{o n}$ is remaining constant with the lowest value $(17 \mu \mathrm{s})$ and the overall duration $(t)$. The interpretation and conclusions are drawn on the function preservation analyzed as the ratio of the area of FTIR vibration bands $\mathrm{C}=\mathrm{C} /$ aliphatic $\mathrm{C}-\mathrm{H}(\mathrm{CC} / \mathrm{CH})$ and $\mathrm{C}=\mathrm{O} / \mathrm{C}-\mathrm{H}(\mathrm{CO} / \mathrm{CH})($ Table 1$)$.

\begin{tabular}{c|c|c|c}
\multicolumn{4}{|c}{ Table 1: wavenumber area of the different FTIR vibration bands } \\
& C=C band & C-H band & C=O band \\
\hline Ac & $1576-1695 \mathrm{~cm}^{-1}$ & $1320-1489 \mathrm{~cm}^{-1}$ & $1626-1770-\mathrm{cm}^{-1}$ \\
\hline AA & $1507-1741 \mathrm{~cm}^{-1}$ & $1316-1490 \mathrm{~cm}^{-1}$ & $1635-1813 \mathrm{~cm}^{-1}$ \\
\hline MA & $1564-1715 \mathrm{~cm}^{-1}$ & $1326-1493 \mathrm{~cm}^{-1}$ & $1626-1824 \mathrm{~cm}^{-1}$
\end{tabular}

Their respective FTIR spectra are fully described later. The DoE with MA precursor was not realized because the $P$ variation domain allowing a stable plasma phase was too weak.

Table 2: Effect (diagonal terms) and interaction (extra-diagonal terms) values calculated from the DoE with different factors for $\mathrm{pp}-\mathrm{Ac}(\mathrm{CC} / \mathrm{CH}$ response).

\begin{tabular}{c|c|c|c|c}
\hline Factor & $t_{\text {off }}(\mu \mathrm{s})$ & $P(\mathrm{~W})$ & $Q(\mathrm{sccm})$ & $t(\mathrm{~min})$ \\
\hline$t_{\text {off }}(\mu \mathrm{s})$ & 0.06 & 0.08 & 0.2 & 0.01 \\
$P(\mathrm{~W})$ & & 0.06 & -0.03 & -0.07 \\
$Q(\mathrm{sccm})$ & & & -0.06 & -0.20 \\
$t(\mathrm{~min})$ & & & & -0.21 \\
\hline
\end{tabular}

The results of pp-Ac given in Table 2 show that the effect of overall duration has a strong and negative impact on $\mathrm{CC} / \mathrm{CH}$. Longer the plasma deposition takes place, lower the double bond appearance is. The other effects are negligible. The interaction of overall duration and $\mathrm{C}_{2} \mathrm{H}_{2}$ flow is also negative while that one between extinction duration and flow enhances the $\mathrm{CC} / \mathrm{CH}$. The interpretation of interactions with the gas flow is complicated, probably due to the complex interdependence of the two plasma parameters: pressure and flow that control the number of precursor molecules per minute in the plasma chamber. Nevertheless, the positive effect of the interaction flow and off-time on the double bond concentration in pp-Ac could be explained by the energy deficient regime described by Yasuda [2]. In this regime, the plasma phase is more and 
more rich in precursor molecules compared to the electron density leading to less fragmentation. The former interaction ( $t$ and $Q$ ) could be linked to a surface chemistry of growing pp-Ac dependence on overall duration further confirmed. The DoE indicates that at least, high $\mathrm{C}_{2} \mathrm{H}_{2}$ flow and low overall duration must be applied.

Table 3: Effect (diagonal terms) and interaction (extra-diagonal terms) values calculated from the DoE with different factors for pp-AA.

\begin{tabular}{c|ccc|ccc}
\hline & \multicolumn{3}{|c|}{ CC/CH response } & \multicolumn{3}{c}{ CO/CH response } \\
\hline Factor & $t_{\text {off }}(\mu \mathrm{s})$ & $P(\mathrm{~W})$ & $t(\min )$ & $t_{\text {off }}(\mu \mathrm{s})$ & $P(\mathrm{~W})$ & $t(\mathrm{~min})$ \\
\hline$t_{\text {off }}(\mu \mathrm{s})$ & 0,36 & $-0,19$ & $-0,06$ & $-0,48$ & $-0,15$ & $-0,19$ \\
$P(\mathrm{~W})$ & & $-0,19$ & 0,02 & & 0,42 & 0,21 \\
$t(\mathrm{~min})$ & & & $-0,25$ & & & 0,86 \\
\hline
\end{tabular}

In case of pp-AA (Table 3), the effects of each factor on $\mathrm{CC} / \mathrm{CH}$ and $\mathrm{CO} / \mathrm{CH}$ are equally significant but opposite. Increasing $t_{\text {off }}$ leads to an increase of $\mathrm{CC} / \mathrm{CH}$ in pp-AA due to less energetic species, but a decrease of its $\mathrm{CO} / \mathrm{CH}$ ratio explained by the action of long life-time radicals, UV and VUV radiation on weaker bonds (carbonyl bond energy $=7.7 \mathrm{eV}$ against $10 \mathrm{eV}$ for triple carbon-carbon bond). These species and photons are able to react with the chromophore carbonyl group as noticed by Yasuda et al. $[2,40]$. The rise of the discharge power decreases the $\mathrm{CC} / \mathrm{CH}$ ratio but $\mathrm{CO} / \mathrm{CC}$ ratio rises up. This behavior is significant of a more pronounced fragmentation under high electronic impact. Moreover, increasing the input energy gives evidence of surface radical appearance and possible post-oxidation. Short overall duration is in favor of $\mathrm{CC} / \mathrm{CH}$ in ppAA while its $\mathrm{CO} / \mathrm{CH}$ rises up for long duration. This fact leads to the same conclusion as previously: if the growing pp-AA is exposed to high energy level or long duration, the created radicals are oxidized after the plasma deposition. The study of interactions for pp-AA shows the importance of the discharge power and the off, overall times. Increasing $t_{\text {off }}$ and $P$ decreases both ratio but increasing $t$ and $P$ only rises up $\mathrm{CO} / \mathrm{CH}$. This should be interpreted as a possible post-oxidation. The main conclusion of this specific DoE is based on which the surface chemistry is requested: surface rich in $\mathrm{C}=\mathrm{C}$ or in $\mathrm{C}=\mathrm{O}$ functions. We chose to focus the study on $\mathrm{CC} / \mathrm{CH}$ ratio with long

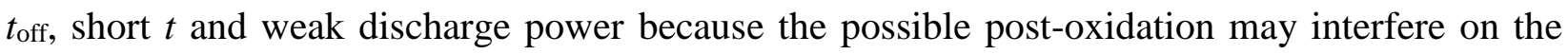
FTIR data.

So finally, from this DoE, one may propose as optimal operating parameters as following (Table 4): 


\begin{tabular}{|c|c|c|}
\hline $\mathrm{pp}-\mathrm{Ac}$ & $\begin{array}{c}P=50 \mathrm{~W}, Q=40 \mathrm{sccm}, t_{\text {off }}=184 \mu \mathrm{s} \text { (frequency }=5 \mathrm{kHz}, \\
\text { duty cycle }=8 \%), t=1 \mathrm{~min}\end{array}$ & $\mathrm{CC} / \mathrm{CH}=2.78$ \\
\hline pp-AA & $\begin{array}{c}P=10 \mathrm{~W}, t_{\text {off }}=184 \mu \mathrm{s} \text { (frequency }=5 \mathrm{kHz}, \text { duty cycle }=8 \%, \\
\text { pressure }=0.01 \text { mbar) }, t=5 \mathrm{~min}\end{array}$ & $\mathrm{CC} / \mathrm{CH}=2.20, \mathrm{CO} / \mathrm{CH}=1.17$ \\
\hline pp-MA & $\begin{array}{c}P=10 \mathrm{~W}, t_{\text {off }}=184 \mu \mathrm{s} \text { (frequency }=5 \mathrm{kHz}, \text { duty cycle }=8 \%, \\
\text { pressure }=0.01 \text { mbar) }, t=20 \mathrm{~min} .\end{array}$ & $\mathrm{CC} / \mathrm{CH}=0.57, \mathrm{CO} / \mathrm{CH}=0.99$ \\
\hline
\end{tabular}

Since the variation domain of the different plasma parameters is too narrow for running the DoE, these conditions are further applied for the MA polymerization with a longer overall duration as further explained. Just note that Siffer F. et al. [39] applying the same type of factorial design but for another plasma chamber showed results in a good agreement. The highest maleic anhydride group retention is also obtained under optimal pulsed plasma conditions rather than under continuous discharge. Such a behavior was explained by the lower ion proportion in the plasma phase, the lower polymerization rate but with less degradation of the growing film [41].

Compared to the respective ratio for each polar monomer $(\mathrm{CC} / \mathrm{CH}=2.24$ and $\mathrm{CO} / \mathrm{CH}=$ 2.92 for $\mathrm{AA}$ and $\mathrm{CC} / \mathrm{CH}=2.55$ and $\mathrm{CO} / \mathrm{CH}=3.14$ for $\mathrm{MA}$ ); it appears that AA precursor is less fragmented with $98 \%$ of preserved $\mathrm{C}=\mathrm{C}$ against only $22 \%$ for MA. But in both cases, the polar function is degraded since only $40 \%$ carboxylic acid are preserved and $31 \%$ for the anhydride.

\section{Chemical characterization of plasma polymers prepared in the optimal operating parameters}

Different types of chemical characterization were performed: FTIR spectroscopy in transmission mode, surface analysis methods like XPS and NEXAFS completed with the wettability measurement. Table 5 and Fig. 1 are summarizing all the FTIR data.

Table 5: Assignment of FTIR vibration bands of pp-Ac, pp-AA, pp-MA.

\begin{tabular}{|c|c|c|c|}
\hline Wavenumber $\left(\mathrm{cm}^{-1}\right)$ & pp-Ac & pp-AA & pp-MA \\
\hline 3442 & $v \mathrm{O}-\mathrm{H}$ de $\mathrm{H}_{2} \mathrm{O}$ & $v \mathrm{O}-\mathrm{H}$ de $\mathrm{H}_{2} \mathrm{O}$ & $v \mathrm{O}-\mathrm{H}$ de $\mathrm{H}_{2} \mathrm{O}$ \\
\hline 2965 & $v($ asym $) \mathrm{CH}_{3}$ & $v($ asym $) \mathrm{CH}_{3}$ & $v($ asym $) \mathrm{CH}_{3}$ \\
\hline 2925 & $v\left(\right.$ asym) $\mathrm{CH}_{2}$ & $v($ asym $) \mathrm{CH}_{2}$ & $v$ (asym) $\mathrm{CH}_{2}$ \\
\hline 2856 & $v($ sym $) \mathrm{CH}_{2}$ & $v($ sym $) \mathrm{CH}_{2}$ & $v($ sym $) \mathrm{CH}_{2}$ \\
\hline 1855 & - & - & $v$ (asym) $\mathrm{C}=\mathrm{O}$ \\
\hline 1782 & - & - & $v($ sym $) \mathrm{C}=\mathrm{O}$ \\
\hline 1720 & $v \mathrm{C}=\mathrm{O}$ & $v \mathrm{C}=\mathrm{O}$ & - \\
\hline 1645 & $v \mathrm{C}=\mathrm{C}$ & - & - \\
\hline 1629 & - & $v \mathrm{C}=\mathrm{C}$ & $v \mathrm{C}=\mathrm{C}$ \\
\hline
\end{tabular}




\begin{tabular}{c|c|c|c}
1463 & $\delta \mathrm{CH}_{2}$ & $\delta \mathrm{CH}_{2}$ & $\delta \mathrm{CH}_{2}$ \\
1387 & $\delta(\mathrm{sym}) \mathrm{CH}_{3}$ & $\delta(\mathrm{sym}) \mathrm{CH}_{3}$ & $\delta(\mathrm{sym}) \mathrm{CH}_{3}$ \\
1247,1178 & - & $v \mathrm{C}-\mathrm{O}$ acid & - \\
1084 & $v \mathrm{C}-\mathrm{C}$ & $v \mathrm{C}-\mathrm{C}$ & $v \mathrm{C}-\mathrm{C}$ \\
1008 & - & $\delta \mathrm{C}-\mathrm{O}$ & - \\
659 & $\delta \mathrm{C}-\mathrm{H}$ des $\mathrm{C}=\mathrm{C}$ & - & -
\end{tabular}

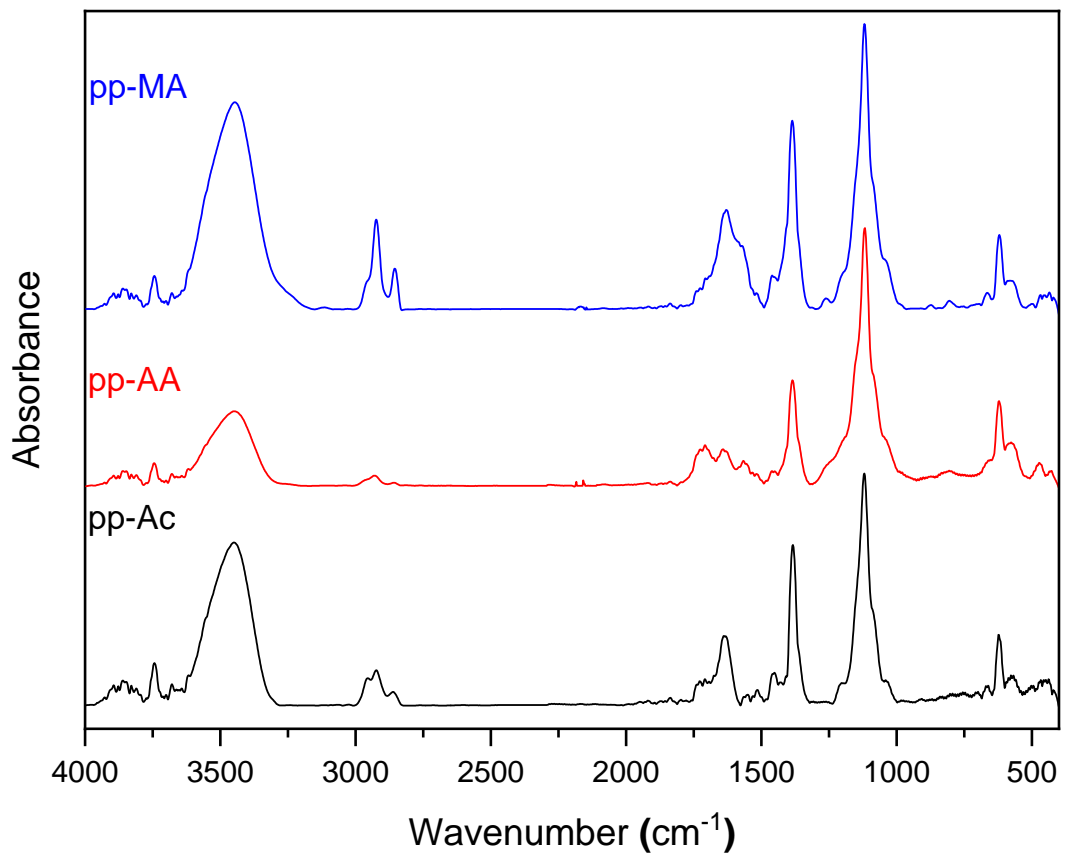

Fig.1: FTIR spectra of pp-Ac, pp-AA, pp-MA prepared in optimal operating parameters.

All the spectra present the vibration bands of $\mathrm{CH}_{\mathrm{x}}$ or C-C bonds (Fig.1 and Table 5). As already described before, the signature of specific functional group of the precursor is noticed (C$\mathrm{C}$ double bond and carbonyl). $\mathrm{Pp}-\mathrm{Ac}$ is oxidized since $\mathrm{C}-\mathrm{O}, \mathrm{C}=\mathrm{O}$ or $\mathrm{C}-\mathrm{OH}$ are assigned, such oxidation corresponds to the dangling radicals formed during the plasma polymerization that age after the treatment $[42,43]$. However, with pp-Ac, this post-oxidation is less pronounced than observed in [42] mostly due to the fact that the storage duration after the deposition and before the FTIR analysis is shorter, few minutes versus two hours. Moreover, such oxidation may also be assigned to oxygen / water desorption from the chamber walls or to acetone plasma fragmentation. Indeed, this molecule is added in the acetylene bottle for safe storage and was interfering in some surface modifications [44]. The pp-AA spectrum shows all the characteristic bands of AA respectively at 1720, 1670 and $1380-1490 \mathrm{~cm}^{-1}$ (Fig.1 and Table 5) and confirm the results obtained by Spanos et al. [45]. The FTIR signature of pp-MA presents one additional and low 
intensity vibration band at $1855 \mathrm{~cm}^{-1}$ assigned to asymmetric stretching of $\mathrm{C}=\mathrm{O}[22,23]$. Moreover, the $\mathrm{CH}_{\mathrm{x}}$ vibration bands are detected, suggesting some MA fragmentations, steeper as reported in [22] but here, the off-time is shorter.

The broad XPS spectra of pp-Ac, pp-AA and pp-MA prepared in optimal conditions are shown in Fig. S1 and their elemental composition given in Table 6.

Table 6: Elemental composition (XPS, \%) of pp-Ac, pp-AA, pp-MA prepared in optimal operating parameters.

\begin{tabular}{l|ccccc}
\multicolumn{7}{c}{$*$ theoretical values of corresponding polymers. } \\
\hline p-Ac* & C 1s & O 1s & N 1s & Si 2p & O/C \\
pp-Ac & 100.0 & - & - & - & - \\
p-AA* & $60 \pm 4$ & $12 \pm 1$ & $2.0 \pm 0.1$ & $6.0 \pm 0.3$ & 0.15 \\
pp-AA & 59.0 & 40.0 & - & - & 0.75 \\
p-MA* & 57.1 & $27 \pm 1$ & $1.0 \pm 0.1$ & $13 \pm 1$ & 0.46 \\
pp-MA & $58 \pm 3$ & 42.9 & - & - & 0.75 \\
\hline
\end{tabular}

The spectra (Fig. S1 and Table 6) of all samples show Si 2p peak in proportions dependent on the polymer nature. This must be interpreted as the signature of the $\mathrm{Si}_{-} \mathrm{SiO}_{2}$ wafer substrate. Indeed, the X-ray penetration in $\mathrm{Si} / \mathrm{SiO}_{2}$ is higher in this relative order of the thickness: pp-Ac < pp-MA $<$ pp-AA. Since the overall duration is longer for MA than AA and Ac, the pp-MA deposit rate is more important, this will be confirmed later by the thickness measurement. Pp-Ac appears to be rich in $\mathrm{C}$ and the observed atomic oxygen around $12 \%$ confirms the FTIR analysis and it is assigned to a post-oxidation. However, this amount is lower than as described in the literature around $17 \%$ and it was shown that the oxidation level was dependent on the plasma purity and the storage duration before XPS analysis [46,47]. Nitrogen atoms in a low concentration (2\%) are also detected, probably assigned to $\mathrm{N}_{2}$ traces in the plasma phase. The two other plasma polymers present almost the same amount of carbon but pp-MA bears more oxygen atoms (33\% against $27 \%$ ). Therefore, its $\mathrm{O} / \mathrm{C}$ is higher justified by different amounts of $\mathrm{Si}$ atoms in both films assigned to the $\mathrm{Si} / \mathrm{SiO}_{2}$ substrate. For almost similar plasma conditions, this $\mathrm{O} / \mathrm{C}$ ratio of pp-MA is higher than the value (0.39) presented in [39] while, with pp-AA, it has the same value as reported in [48].

The $\mathrm{C}$ 1s high resolution spectra of the different deposits allow to clearly identify the polymer functionality (Fig. 2, Table 7). 

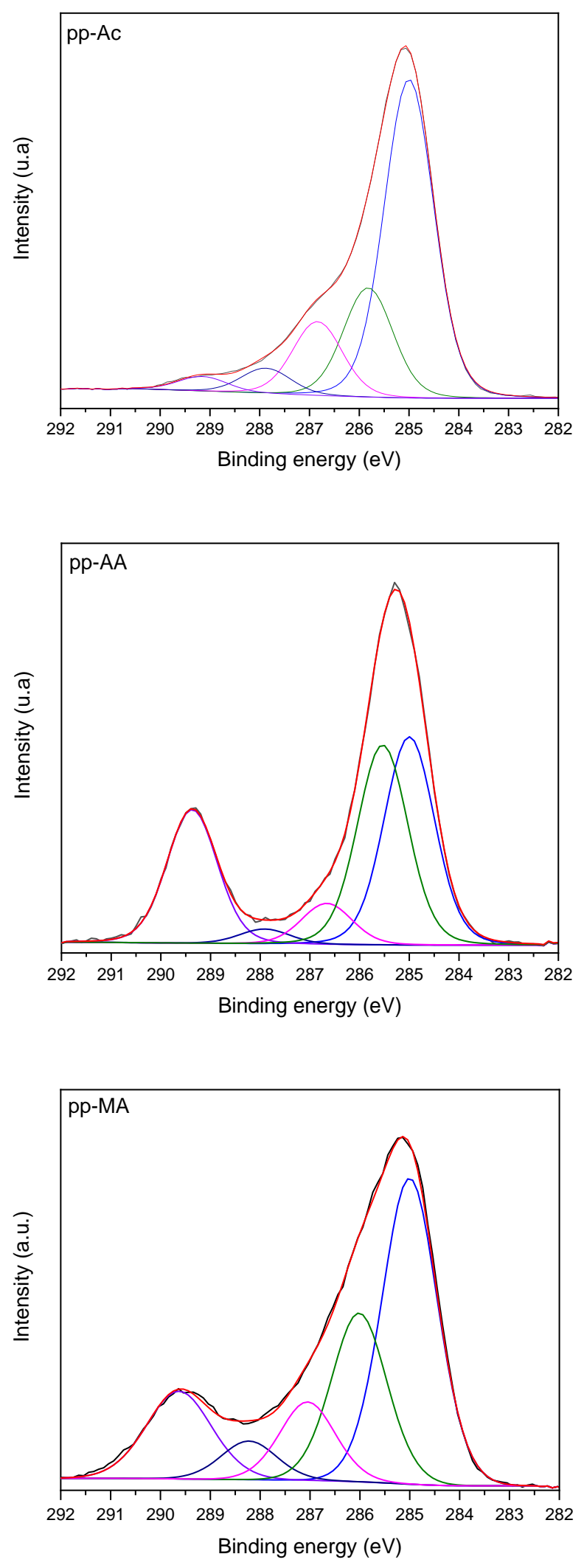

Fig. 2: C 1s high resolution spectra of pp-Ac, pp-AA, pp-MA prepared in optimal operating parameters 
Table 7: Assignment and proportion $(\%)$ of the different sub-structures in pp-Ac, pp-AA, pp-MA prepared in optimal

\begin{tabular}{|c|c|c|c|c|c|}
\hline & $\underline{\mathrm{C}}=\mathrm{C}, \underline{\mathrm{C}}-\mathrm{C} / \underline{\mathrm{C}}-\mathrm{H}$ & $\begin{array}{c}\text { C-COOR, } \\
\text { C-N, } \\
\text { C-OH }\end{array}$ & $\underline{\mathrm{C}}-\mathrm{O}-\mathrm{C}$ & $\underline{\mathrm{C}}=\mathrm{O}$ & $\underline{\text { COOR }}$ \\
\hline Binding energy $(\mathrm{eV})$ & 285.0 & 285.8 & 286.8 & 287.9 & 289.1 \\
\hline $\mathrm{pp}-\mathrm{Ac}$ & 63.1 & 20.6 & 10.1 & 4.0 & 2.2 \\
\hline pp-AA & 34.8 & 33.4 & 6.9 & 2.5 & 22.4 \\
\hline pp- MA & 44.0 & 24.3 & 11.3 & 5.6 & 14.8 \\
\hline
\end{tabular}

First of all, the three spectra present the same sub-structures but in different proportions (Fig. 2, Table7). The most important one at $285.0 \mathrm{eV}$ is assigned to $\mathrm{C}-\mathrm{C} / \mathrm{C}-\mathrm{H}$ and probably $\mathrm{C}=\mathrm{C}$ which normally appears at a close value $(284.7 \mathrm{eV})$ [49]. The substructure at $285.8 \mathrm{eV}$ is assigned to $\underline{\mathrm{C}}-\mathrm{COOR}, \underline{\mathrm{C}}-\mathrm{N}, \underline{\mathrm{C}}-\mathrm{OH}$ while peaks at $286.8,287.9$ and $289.1 \mathrm{eV}$ are respectively attributed to $\underline{\mathrm{C}}-\mathrm{O}-\mathrm{C}, \underline{\mathrm{C}}=\mathrm{O}$ and $\underline{\mathrm{COOR}}$. For pp-Ac, sp2 and sp3 carbons appear under the same peak in a low proportion. Furthermore, in both cases, carbon oxygen bonds are assigned around 20 - $30 \%$ due to post-oxidation. The retention of the chemical function of plasma poly(acrylic acid) is confirmed with a high proportion (22\%) but other sub-structures (hydroxyl, ketone, aldehyde) in smaller proportions are noticed. As described Palumbo et al [50], smooth plasma conditions; i.e. low discharge power, induce the appearance of few new oxidized groups like $\mathrm{C}-\mathrm{O}$ and preserve the initial precursor structure (carboxylic function). In a same manner, pp-MA present few new functions like $\mathrm{C}-\mathrm{OH}$ at $286.8 \mathrm{eV}(\approx 11 \%)$ but with this specific polymer and analysis, it is rather difficult to distinguish acid/ester and anhydride groups. However, from the literature, same conclusion can be drawn than with pp-AA: lower discharge power or long $t_{\text {off }}$ enhance the function retention $[23,24,39]$. 

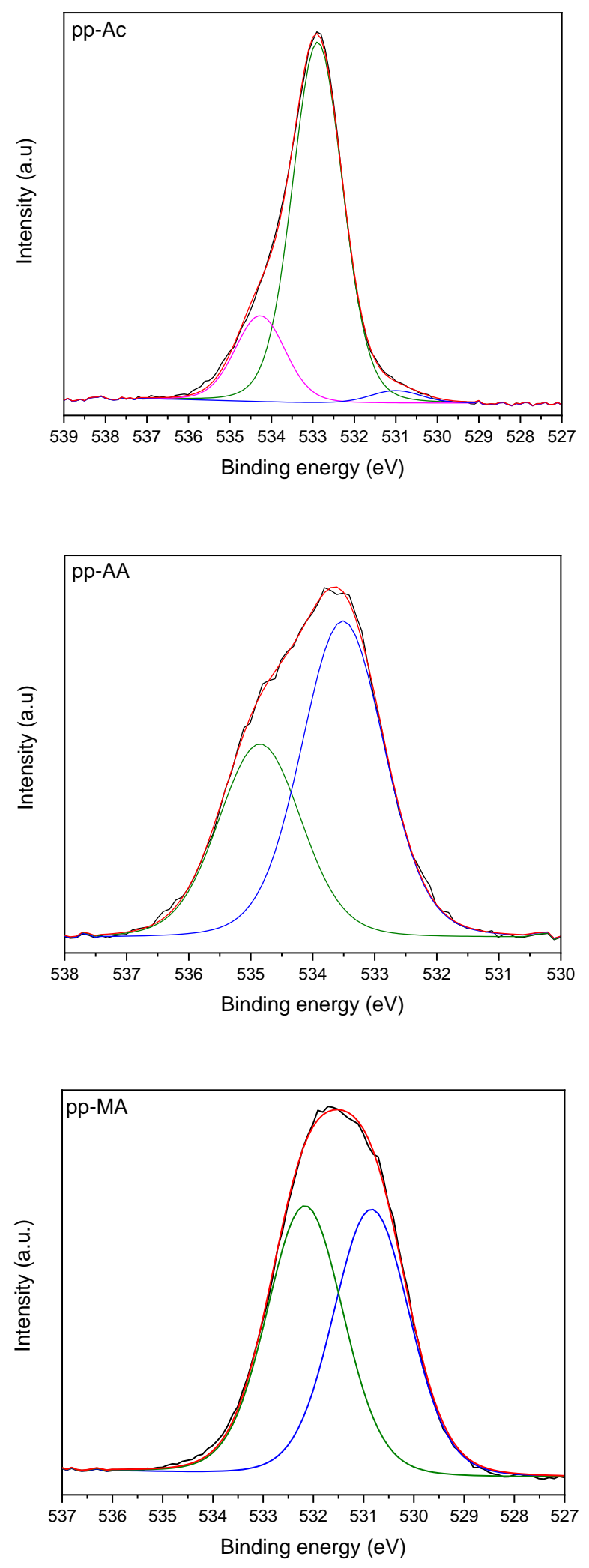

Fig. 3: O 1s high resolution spectra of pp-Ac, pp-AA, pp-MA prepared in optimal operating parameters 
Table 8: Assignment and proportion $(\%)$ of the different sub-structures in pp-Ac, pp-AA, pp-MA prepared in optimal operating parameters

\begin{tabular}{ccccc}
\hline & $\underline{\mathrm{O}}=\mathrm{C}$ & $\mathrm{O}-\mathrm{C}=\underline{\mathrm{O}}$ & Ho-C, & C--ㅡ-C \\
\hline $\begin{array}{c}\text { Binding energy } \\
(\mathrm{eV})\end{array}$ & 531.0 & 532.2 & $532.9-533.3$ & 534.2 \\
\hline pp-Ac & 2.5 & - & 78.7 & 18.8 \\
pp-AA & - & 62.1 & 37.9 & - \\
pp-MA & 49.8 & 50.2 & - & - \\
\hline
\end{tabular}

O 1s high resolution peak of pp-Ac (Fig. 3, Table 8) shows substructures due to the polymer ageing that are mostly assigned to hydroxyl at $532.9 \mathrm{eV}$ and ether at $534.2 \mathrm{eV}$, carbonyl at 531.0 $\mathrm{eV}$. For pp-AA, the preponderant component is the carboxylic acid group with two substructures at $532.2 \mathrm{eV}$ and its attached hydroxyl at $533.3 \mathrm{eV}$. Their proportions are not equivalent probably explained by the creation of carbonate/anhydride or branched functions. In the case of pp-MA, the $\mathrm{O} 1 \mathrm{~s}$ peak is only composed of two components in a same proportion as already described in $[23,51]$.

Compared to FTIR spectroscopy, the XPS analysis confirmed the $\mathrm{COOH}$ and anhydride retention but did not give any details on the respective proportion of $\mathrm{sp} 2$ and $\mathrm{sp} 3$ carbons. Therefore, the surface sensitive NEXAFS (10 nm for total electron yield-TEY, few nanometers for partial electron-PEY) was performed. 

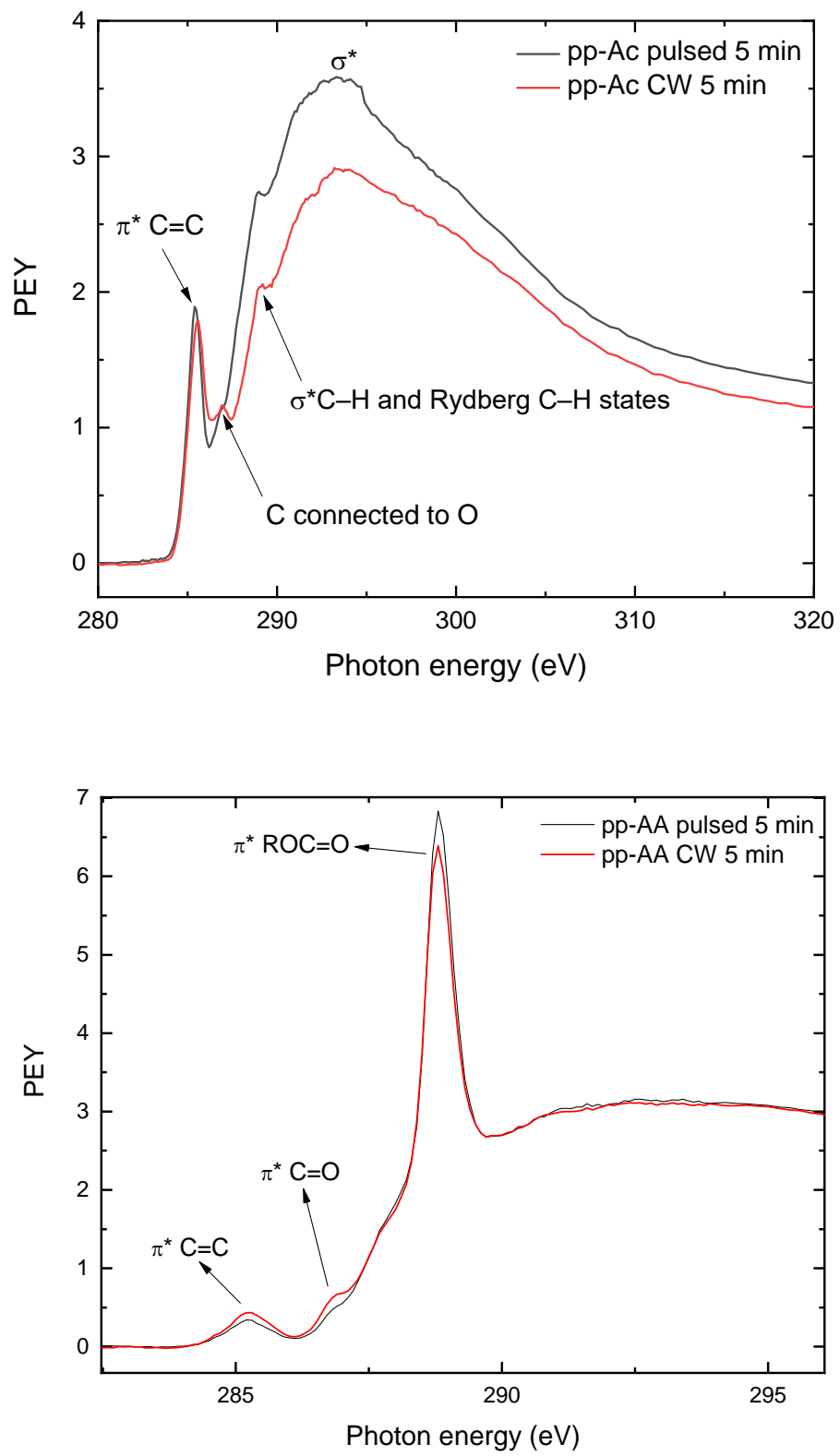


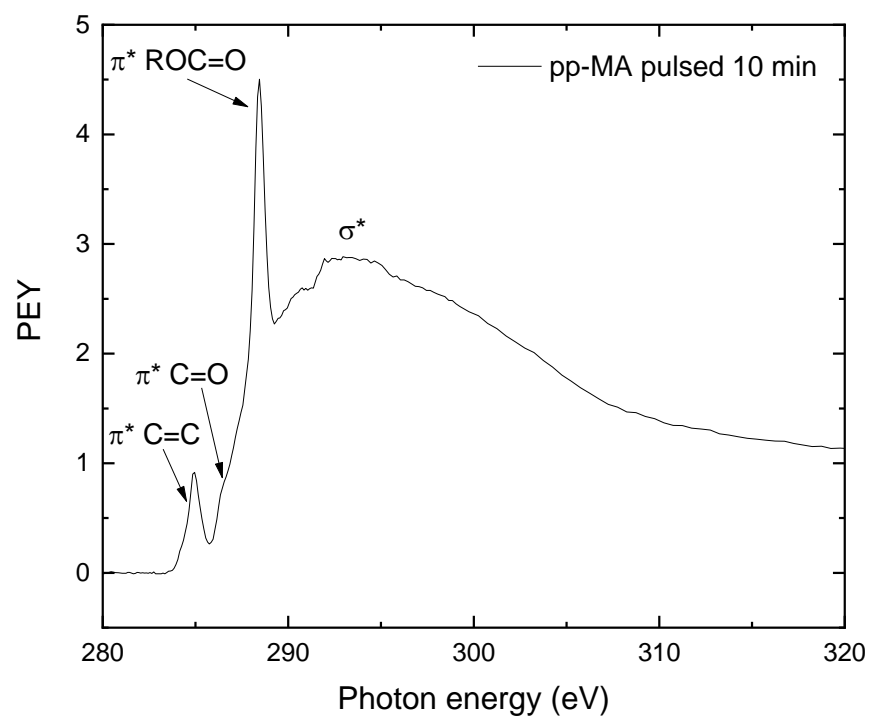

Fig. 4: Carbon NEXAFS spectra of pp-Ac, pp-AA, pp-MA prepared in different operating parameters. Black line: in pulsed optimized plasma except pp-MA with a shorter duration; red line: in continuous discharge, $P=50 \mathrm{~W}$ (pp-Ac), $P=10 \mathrm{~W}$ (pp-AA and pp-MA).

In the carbon NEXAFS spectrum of pp-Ac prepared in both modes (Fig. 4), the continuous wave plasma polymer is shown as a reference for crosslinked polymers. Unsaturated carbon-carbon bond are identified through the intense $\pi \rightarrow \pi^{*}$ resonance at $284.9 \mathrm{eV}$ [42,52] leading to the conclusion that the XPS substructure at $285 \mathrm{eV}$ is composed of sp2 and sp3 carbons (Fig.2, Table 7) as shown with FTIR analysis. The small shoulder at $286.6 \mathrm{eV}$ is assigned to $\pi^{*}$ resonance of $\mathrm{C}=\mathrm{O}$ due to post-oxidation. The nearby shoulder at $289.3 \mathrm{eV}$ is assigned to $\sigma^{*}$ resonance of $\mathrm{C}-\mathrm{C}$ and the broad peak between 294 and $310 \mathrm{eV}$ corresponds to $\mathrm{C}-\mathrm{H} \sigma^{*}$ resonance. However, for ppAc prepared in continuous discharge, the shoulder peak assigned to the post-oxidation is more pronounced meaning higher precursor fragmentation, radical creation and ultimately the postoxidation occurred. The other peaks of $\mathrm{C}-\mathrm{C}$ and $\mathrm{C}-\mathrm{H} \sigma^{*}$ resonances are impacted with a peak broadening and lower base-line (-0.5) [42,52]. NEXAFS C K-edge spectra of pp-AA (Fig. 4) show a small peak on $284.9 \mathrm{eV}$ corresponding to $\pi^{*} \mathrm{C}=\mathrm{C}$ resonance, small shoulder at $286.58 \mathrm{eV}$ assigned to $\pi^{*} \mathrm{C}=\mathrm{O}$ resonance, sharp peak $288.5 \mathrm{eV}$ attributed to $\pi^{*} \mathrm{ROC}=\mathrm{O}$ transition for a carboxylate. The peak at $290.8 \mathrm{eV}$ is assigned to $\sigma^{*} \mathrm{C}-\mathrm{C}$ transition and broad peak in the range 294-300 eV which includes $\sigma^{*}$ resonances associated to the carboxylate species [53]. We can observe a slight difference between pulsed and continuous wave deposition. Sharp peak at 288.3 
$\mathrm{eV}$ is increasing for continuous wave. The peak at $284.8 \mathrm{eV}$ which corresponds to $\pi^{*} \mathrm{C}=\mathrm{C}$ resonances is smaller for pulsed wave and higher for continuous one which means that acrylic acid is decomposed or crosslinking during pulsed wave deposition. Small shoulder at $286.4 \mathrm{eV}$ appears only for CW. There is no big change in the case of $\sigma^{*}$ transition [54].

NEXAFS C K-edge spectra of pp-MA (Fig. 4) is close to that of pp-AA but with much higher $\pi^{*} \mathrm{C}=\mathrm{C}$ peak and pronounced $\sigma^{*}$ region. Its NEXAFS signature is similar to the spectrum of adsorbed precursor as described in $[55,56]$ even if the peaks are broader probably because of its polymeric nature. 

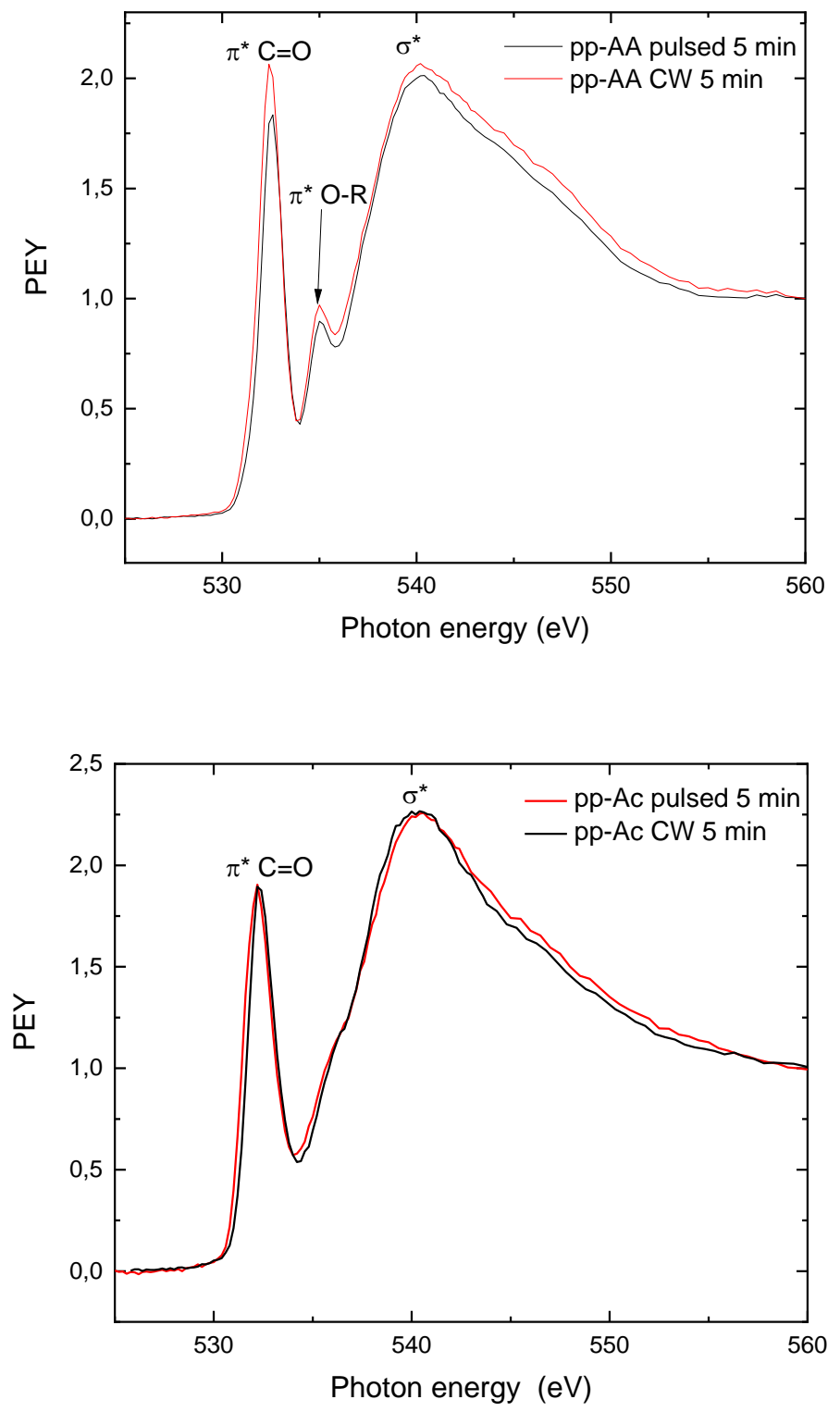


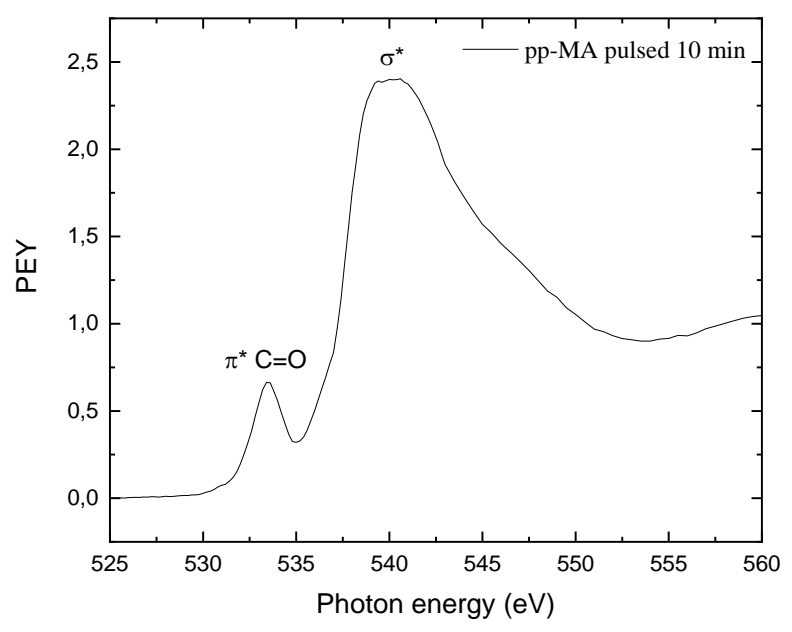

Fig. 5: Oxygen NEXAFS spectra of pp-Ac, pp-AA, pp-MA prepared in optimal operating parameters

In the same way as the XPS analysis, the O K-edge spectra were carried out in order to visualize the presence of the different species and to compare against the other results obtained (Fig. 5). These spectra show for these three polymers a peak at $532.4 \mathrm{eV}$ which corresponds to the resonance of $\pi * \mathrm{C}=\mathrm{O}$ and another broad peak at $540.2 \mathrm{eV}$ for the $\sigma *$ region, which can be connected with $(\mathrm{C}-\mathrm{O})$ carboxylate transition. The pp-Ac spectrum is the result of post-oxidation of the polymer layer. For pp-AA, the peaks are much thinner without broadening compared to the spectrum studied by [53], especially the presence of the acid groups is clearly visible. The only difference for pp-AA is the presence of a small peak at $535.0 \mathrm{eV}$ assigned to the excitation of the oxygen level in the $\pi *$ carboxylate orbital. For pp-MA, the peaks are wider compared to the other two. Both types of bonds are clearly visible like the O1s spectrum of XPS analysis. The broadening of the peaks is also marked regardless of the angle of analysis [55].

\subsection{Wetting of plasma coating and comparison with different model elastomers}

The purpose of the study is to prepare plasma deposit adhesive joint further applied during the elastomer vulcanization. Therefore, the surface chemistry is one of the key points but an appropriate surface functionalization without any good wetting property is useless for the fabrication of cohesive metal-elastomer assembly. So, the surface free energy and its dispersive and non-dispersive components were determined from the measure of contact angle of water and 
diiodomethane. Results were then compared with that one obtained for two model elastomers: the nitrile butadiene rubber (NBR) and the fluoroelastomer (FKM).

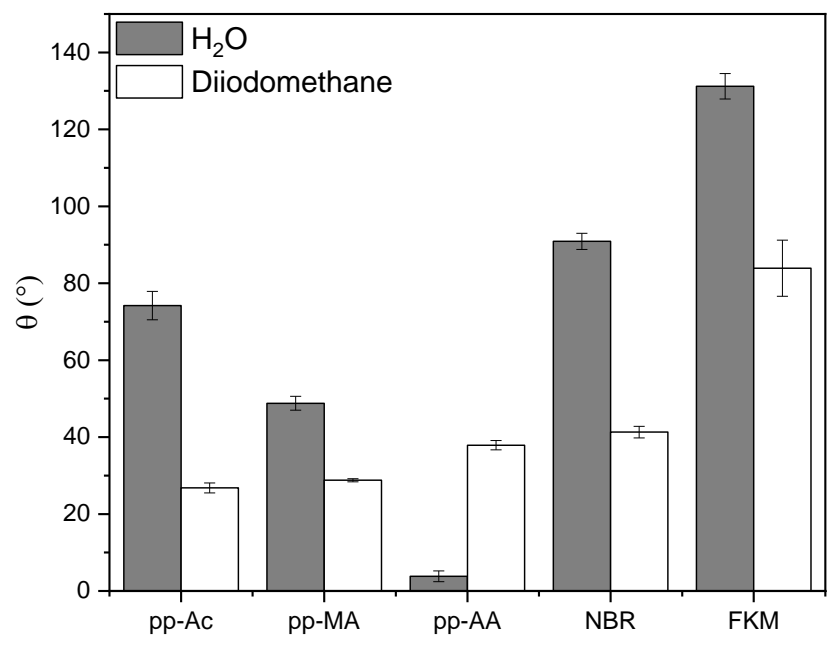

Fig. 6: Contact angle of water or diiomethane drops on pp-Ac, pp-AA, pp-MA, NBR and FKM

As shown on Fig. 6, water contact angles (WCA) vary depending on the nature of the plasma polymer. WCA of pp-Ac is about $74.2 \pm 3.7^{\circ}$, moderate value significant of hydrophobic material such as this hydrocarbon. The pp-MA shows an intermediate value of WCA: $48.8 \pm 1.8^{\circ}$ while pp-AA is almost wet with a WCA around $5.0 \pm 1.4^{\circ}$. These values are similar to those described in the literature [57,58]. Between pp-Ac and pp-MA, there is a factor of 1.5 in terms of WCA then factor of 15 with pp-AA. With diiodomethane contact angle (DCA), the order is reversed: $\mathrm{DCA}_{\mathrm{pp}-\mathrm{Ac}}\left(26.8 \pm 1.3^{\circ}\right)<\mathrm{DCA}_{\mathrm{pp}-\mathrm{MA}}(28.8 \pm 0.4)<\mathrm{DCA}_{\mathrm{pp}-\mathrm{AA}}\left(37.9 \pm 1.2^{\circ}\right)$. As expected, the introduction of oxygenated groups leads to a marked reduction in the contact angle and the surface becomes more hydrophilic, especially for pp-AA and pp-MA. With diiodomethane, an apolar liquid, the angles measured give slightly higher values on a polar surface. The elastomers NBR and FKM have a WCA of $90.9 \pm 1.2^{\circ}$ and $131.2 \pm 3.3^{\circ}$ respectively, $41.3 \pm 1.5^{\circ}$ and $83.9 \pm$ $7.3^{\circ}$ for DCA. The surface of elastomers is more hydrophobic than that of plasma polymers.

The measurement of the contact angles of these two probe liquids also makes possible to determine the total surface $\left(\gamma^{\mathrm{t}}\right)$, dispersive $\left(\gamma^{\mathrm{d}}\right)$ and polar $\left(\gamma^{\mathrm{p}}\right)$ energies of the three plasma polymers and the two elastomers according to the Owens-Wendt method [59] (Fig. 7). 


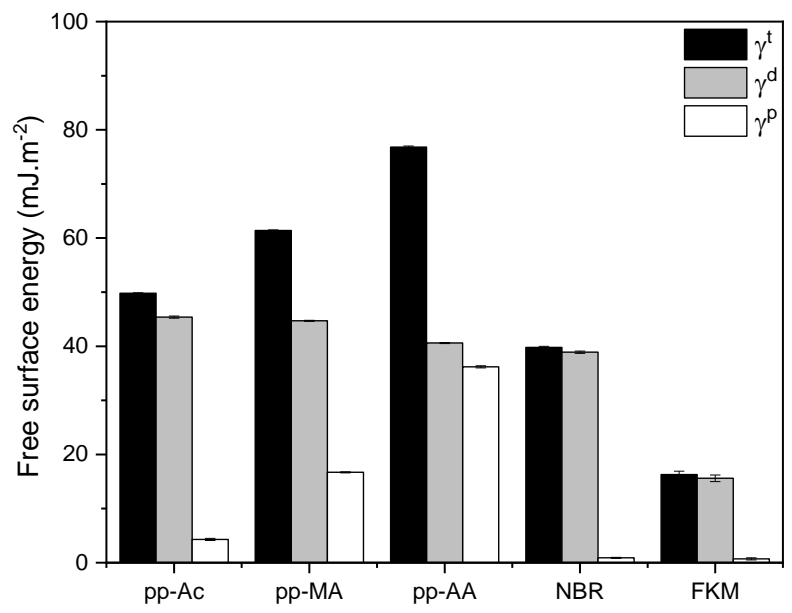

Fig. 7: Surface free energy of pp-Ac, pp-AA, pp-MA, NBR and FKM

The surface free energies of pp-Ac, pp-MA and pp-AA are increasing from $49.8 \pm 0.1$ to $76.8 \pm 0.2 \mathrm{~mJ} . \mathrm{m}^{-2}$. The dispersive component remains almost constant whatever the plasma polymers around $42.5 \pm 0.2 \mathrm{~mJ} . \mathrm{m}^{-2}$. As observed with WCA, the polar energy is increasing in the same order pp-Ac < pp-MA < pp-AA $4.3 \pm 0.2$ to $36.2 \pm 0.2 \mathrm{~mJ} . \mathrm{m}^{-2}$. The surface free energy of NBR and FKM are respectively $39.8 \pm 0.2$ and $16.3 \pm 0.6 \mathrm{~mJ}^{-2} \mathrm{~m}^{-2}$. The preparation of cohesive metal-elastomer assembly implies at least surface free energy in a same order for the adhesive joint, i.e. the plasma polymer, and for the elastomer. Since their respective surface energies, pp-Ac and NBR should induce a cohesive assembly.

\subsection{Plasma polymerization kinetics for enhancing film thickness}

In the previous sections, the chemical composition and the surface free energy structure were studied to promote chemical and thermodynamic adhesions. This part is focusing on the influence of the deposition kinetics controlling the film thickness, a parameter which ultimately promotes the diffusion of the polymer chains and which creates an interphase between the two substrates in contact (plasma polymer and elastomer). The correlation between the thickness and the chemical structure of the plasma polymer according to the variation of time will thus be studied.

Plasma polymerization kinetics: 
The deposition kinetics study is carried out in order to determine the deposition rate under the various optimized conditions. The film growth is assessed by AFM measurement of the thicknesses at different deposition times and Fig. 8 shows the thickness dependence for the pp-Ac, pp-AA and pp-MA films.

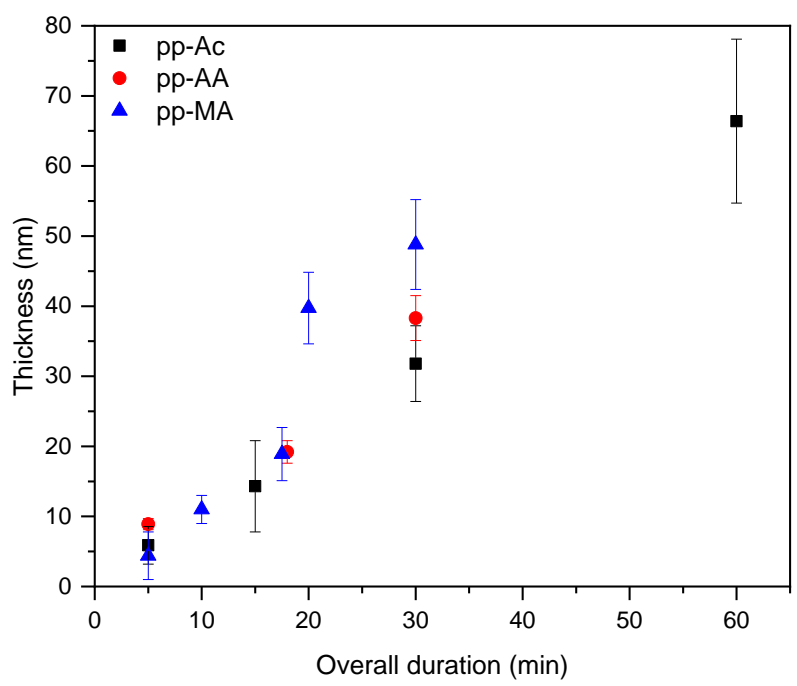

Fig. 8: Dependence of the three plasma polymers thickness on the overall duration.

In the studied time domain, the thickness of the three plasma polymers variation is almost linearly dependent on duration (Fig. 8) and therefore meaning that the density of reactive plasma species does not vary with time with few degradation process [2]. The deposit rates of pp-Ac, ppAA and pp-MA are $1.08 \pm 0.03$ nm. in $^{-1}, 1.25 \pm 0.17$ nm. min $^{-1}, 1.38 \pm 0.18 \mathrm{~nm} \cdot \mathrm{min}^{-1}$, respectively. This kinetic study explains why the Si peak was detected in XPS analysis. The layer thickness is weaker, 1.1, 6.2 and $27.6 \mathrm{~nm}$ for pp-Ac, pp-AA and pp-MA respectively. At same plasma conditions (AA and MA deposit), thicker the deposit is (case of pp-MA), weak the Si concentration ( $8 \%$ against $12.7 \%$, cf Table 6 ) is. Pp-Ac deposition rate cannot be compared because of different plasma conditions $(P=50 \mathrm{~W})$ and a too different chemical structure of the precursor.

\section{Relationship between thickness and chemical composition of the plasma polymers:}

If the plasma is considered as an equilibrium medium, the time parameter only affects the deposited thickness without any influence on the chemical structure of the deposit layer. However, the DoE shows that it influences the chemical composition. 

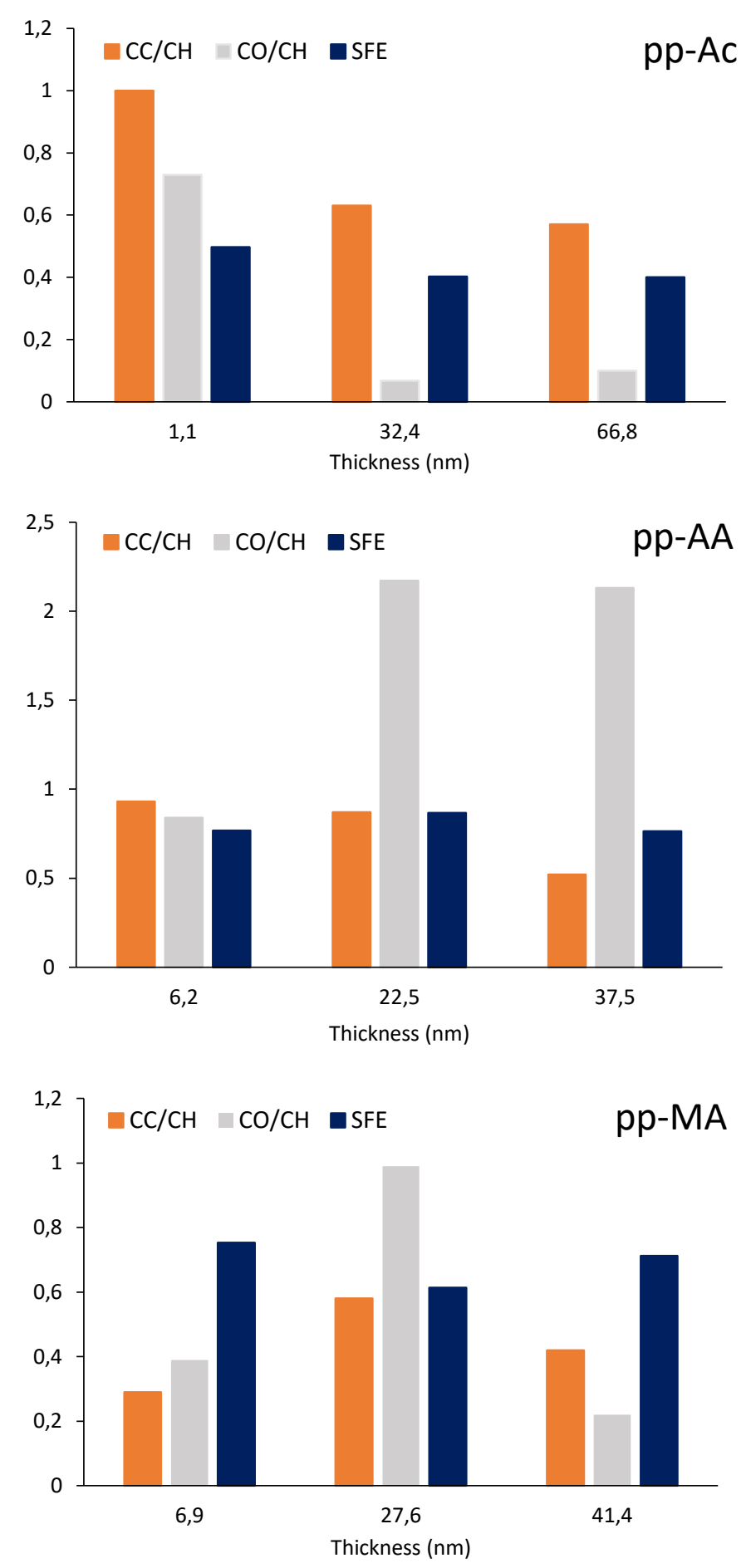

Fig. 9: Relationship between the overall thickness and the chemical structure of the three plasma polymers determined by FTIR ratio $(\mathrm{CC} / \mathrm{CH}, \mathrm{CO} / \mathrm{CH})$, surface free energy $(\mathrm{SFE})\left(10^{+2} \mathrm{~mJ} . \mathrm{m}^{-2}\right)$.

Indeed, the Fig. 9 shows that the chemical composition of the different plasma polymers is dependent on the overall thickness and therefore on the duration as also observed in [36,58]. In 
case of pp-Ac, the $\mathrm{CC} / \mathrm{CH}, \mathrm{CO} / \mathrm{CH}$ are strongly decreasing while the SFE is almost constant. Beside the possible post-ageing leading to the polar groups attachment, pp-Ac surface does not vary with the duration because it is quickly oxygen-saturated. The decrease of $\mathrm{CC} / \mathrm{CH}$ and $\mathrm{CO} / \mathrm{CH}$ ratio related to the bulk structure such behaviors should indicate bulk reorganization leading to a cross-linked and less oxidized network. This time-dependence is probably due to ion accumulation in the hydrocarbon film and a progressive increase of the substrate temperature as observed [60]. The behavior of the hydrophilic plasma polymers is not similar. Indeed, with pp-AA, CC/CH and $\mathrm{CO} / \mathrm{CH}$ ratio contradictory vary with a more pronounced rise for the second one. Surface energy is almost constant. As observed with pp-Ac, the disappearance of $\mathrm{C}=\mathrm{C}$ may be due to cross-linking (or chain growth) because of the substrate heating under ionic bombardment and charge surface accumulation for long duration as described in [2]. The increase of the $\mathrm{C}=\mathrm{O}$ FTIR signature must also be interpreted as bulk reorganization during precursor fragmentation and polymer growth rather than ageing since the surface free energy did not vary. The dependence of pp-MA chemical structure on the thickness and the duration is more complex; it passes through a maximum corresponding to the optimal plasma parameters. Long duration induces a decrease of both functionalities $(\mathrm{C}=\mathrm{C}$ and $\mathrm{C}=\mathrm{O})$ and should be assigned to the competitive degradation during the plasma deposition [2].

\section{Conclusion}

The study of the Ac, AA and MA plasma-polymerization was focused on the preparation of highly functionalized deposit in order to enhance the adhesion of elastomer. Pulsed plasma following the DoE was explored for controlling the surface function density by limiting the electron, ion bombardments and the precursor fragmentation. The parameters as the discharge power, the gas flow, the plasma extinction time and the overall duration were selected on the basis of the function preservation analyzed as the ratio of the different FTIR vibration bands $\mathrm{CC} / \mathrm{CH}$ and $\mathrm{CO} / \mathrm{CH}$. Specific plasma operating conditions were found for each precursor using the DoE.

Then, the obtained layers were characterized in bulk (FTIR spectroscopy), at the surface (like XPS and NEXAFS completed with the wettability measurement). Pp-Ac bears sp3 and sp2 carbons, evidence of the latter one is given by FTIR and NEXSAF spectroscopies. This deposit is partially post-oxidized. The retention of the acidic function of pp-AA is confirmed with a high 
proportion but other sub-structures (hydroxyl, ketone, aldehyde) in smaller proportions are noticed. In a same manner, pp-MA presents few new functions like hydroxyl. In conclusion, the plasmapolymers may act as chemical adhesive joint during the elastomer vulcanization.

However, the fabrication of cohesive metal-elastomer assembly requests appropriate surface functionalization and wetting property. The surface free energies of pp-Ac, pp-MA and ppAA varied from $\approx 50$ to $77 \mathrm{~mJ} . \mathrm{m}^{-2}$ and their polar component is increasing in the order of pp-Ac < pp-MA < pp-AA. Since the surface energy of model elastomers (NBR and FKM) are around 40 and $16 \mathrm{~mJ} . \mathrm{m}^{-2}$, only pp-Ac and NBR should induce a cohesive assembly.

The study was also focused on the influence of the deposition kinetics controlling the film thickness, a parameter which ultimately promotes the diffusion of the polymer chains and the appearance of an interphase between the two materials in contact. The thickness of the three plasma polymers variation is almost linearly dependent on duration and therefore meaning that the density of reactive plasma species does not vary with time without any degradation process. However, the chemical composition of the different plasma polymers is dependent on the overall thickness and therefore on the duration. Such behavior was associated to indirect charge surface accumulation and substrate heating that led to crosslinking and bulk reorganization of the different plasma polymers.

\section{Acknowledgments}

This study is part of the Plasma-Bond project supported by the French agency ANR. The authors wish to acknowledge and to associate the industrial and academic partners of this project; respectively EFJM, Safran.

Experiments at BESSY have been also supported with H2020 Calypso Plus project, grant Nr. 19208646-ST ,18207084-ST and 18207393-ST. We gratefully acknowledge HBZ for the allocation of the beamtime.

\section{References}

[1] L. Picard, P. Phalip, E. Fleury, F. Ganachaud. Bonding of silicone rubbers on metal (2) physical chemistry of adhesion. Prog. Org. Coat. 87 (2015) 258-266. https://doi: 10.1016/j.porgcoat.2015.03.020.

[2] H. K. Yasuda Plasma Polymerization; Academic Press: New York, 1985. 
[3] K. J. Kim, N. E. Lee, M. C. Kim, J.-H Boo. Chemical interaction, adhesion and diffusion properties at the interface of $\mathrm{Cu}$ and plasma-treated thiophene-based plasma polymer (ThioPP) films. Thin Solid Films, 398 (2001) 657-662. https://doi.org/10.1016/S0040-6090(01)01372-4.

[4] H. Kobayashi, A. T. Bell, M. Shen, Effects of monomer flow rate, flow configuration, and reactor geometry on the rate of plasma polymerization. J. Macromol. Sci. Part - Chem. 10 (1976) 491-500. https://doi.org/10.1080/00222337608061195.

[5] Y. Martin, D. Boutin, P. Vermette. Study of the effect of process parameters for N-heptylamine plasma polymerization on final layer properties. Thin Solid Films 515 (2007) 6844-6852. https://doi.org/10.1016/j.tsf.2007.02.002.

[6] Peter, S.; Günther, M.; Hauschild, D.; Grambole, D.; Richter, F. Mid-frequency deposition of a-C:H films using five different precursors. Vacuum 2010, 85, 510e513. https://doi.org/10.1016/j.vacuum.2010.10.006.

[7] Berndt, J.; Kovačević, E.; Stefanović, I.; Boufendi, L. Controlled dust formation in pulsed rf plasmas. J. Appl. Phys. 2009, 106, 063309. https://doi.org/10.1063/1.3224874.

[8] T. Schwarz-Selinger, A. von Keudell, W. Jacob. Plasma chemical vapor deposition of hydrocarbon films: The influence of hydrocarbon source gas on the film properties. J. Appl. Phys. 86 (1999) 3988. https://doi.org/10.1063/1.371318.

[9] G. Capote, E. J. Corat, V. J. Trava-Airoldi. Deposition of amorphous hydrogenated carbon films on steel surfaces through the enhanced asymmetrical modified bipolar pulsed-DC PECVD method. Surf. Coat. Technol. 260 (2014) 133-138. http://dx.doi.org/10.1016/j.surfcoat.2014.09.046.

[10] S. Peter, M. Günther, F. Richter. A comparative analysis of a-C:H films deposited from five hydrocarbons by thermal desorption spectroscopy. Vacuum 86 (2012) 667e671. https://doi.org/10.1016/j.vacuum.2011.07.037.

[11] S. Kumar, P. N. Dixit, D. Sarangi, R. Bhattacharyy, Possible solution to the problem of high built-up stresses in diamond-like carbon films. J. Appl. Phys. 85 (1999) 3866. https://doi.org/10.1063/1.369758.

[12] H. Yasuda, T. Hsu. Some aspects of plasma polymerization investigated by pulsed R.F. discharge. J. Polym. Sci. Polym. Chem. 15 (1977) 81-97. https://doi.org/10.1002/pol.1977.170150109.

[13] L. Zajickova, S. Rudakowski, H. W. Becker, D. Meyer, M. Valtr, K. Wiesemann. Study of plasma polymerization from acetylene in pulsed r.f. discharges. Thin Solid Films 425 (2003) $72-$ 84. https://doi.org/10.1016/s0040-6090(02)01133-1.

[14] S. Fraser, R. D. Short, D. Barton, J. W. Bradley, A multi-technique investigation of the pulsed plasma and plasma polymers of acrylic acid: millisecond pulse regime. J. Phys. Chem. B

106 (2002) 5596-5603. https://doi.org/ 10.1021/jp012406j.

[15] S. A. Voronin, J. W. Bradley, C. Fotea, M. Zelzer, M. R. Alexander. Characterization of thinfilm deposition in a pulsed acrylic acid polymerizing discharge J. Vac. Sci. Technol. A 25 (2007) 1093-1097. https://doi.org/10.1116/1.2712186.

[16] M. Dhayal, J. W. Bradley. Using heated probes in plasma polymerising discharges. Surf. Coat. Technol. 184 (2004) 116-122. https://doi.org/10.1016/j.surfcoat.2003.10.005.

[17] M. Dhayal, J. W. Bradley. Time-resolved electric probe measurements in the pulsed-plasma polymerisation of acrylic acid. Surf. Coat. Technol. 194 (2005) 167-174. https://doi.org/10.1016/j.surfcoat.2004.05.013.

[18] S. A. Voronin, M.R. Alexander ,J.W. TBradley ime-resolved mass and energy spectral investigation of a pulsed polymerising plasma struck in acrylic acid. Surf. Coat. Technol. 201 (2006) 768-775. https://doi.org/10.1016/j.surfcoat.2005.12.031. 
[19] M. Dhayal. Use of Different size grids to control the surface chemistry of plasma-polymerized acrylic acid films in a hybrid discharge. J. Appl. Polym. Sci. 104 (2007) 2219-2224. https://doi.org/ 10.1002/app.25471.

[20] S. A. Evenson, C. A. Fail, J. P. S. Badyal, Controlled monomolecular functionalization and adhesion of solid surfaces. Chem. Mater., $12 \quad$ (2000) 3038-3043. https://doi.org/10.1021/cm000223o.

[21] A. T. A. Jenkins, J. Hu, Y. Z. Wang, S. Schiller, R. Foerch, W. Knoll Pulsed plasma deposited maleic anhydride thin films as supports for lipid bilayers. Langmuir 16 (2000) 6381-6384. https://doi.org/10.1021/la991649o.

[22] V. Roucoules, C. A. Fail, W. Schofield, C. E. Declan, O. H. Teare, J. P. S. Badyal. Diels-alder chemistry on alkene functionalized films. Langmuir 21 (2005) 1412-1415. https://doi.org/10.1021/la0479657.

[23] S. Schiller, J. Hu, A. T. A. Jenkins, R. B. Timmons, F. S. Sanchez-Estrada R. Foerch, W. Knoll. Chemical structure and properties of plasma-polymerized maleic anhydride film. Chem. Mater., 14 (2002) 235-242. https://doi.org/10.1021/cm011139r.

[24] M. E. Ryan, A. M. Hynes, J. P. S. Badyal. Pulsed plasma polymerization of maleic anhydride Chem. Mater. 8 (1996) 37-42. https://doi.org/1021/cm9503691.

[25] A. Nefedov, C. Wöll, (2013) Advanced Applications of NEXAFS Spectroscopy for Functionalized Surfaces. In: Bracco G., Holst B. (eds) Surface Science Techniques. Springer Series in Surface Sciences, vol 51. Springer, Berlin, Heidelberg. https://doi.org/10.1007/978-3-64234243-1_10.

[26] E. Kovacevic, J. Berndt, T. Strunskus, L. Boufendi. Size dependent characteristics of plasma synthesized carbonaceous nanoparticles. J. Appl. Phys. 112 (2012) 013303. https://doi.org/10.1063/1.4731751.

[27] S. Swaraj, U. Oran, A. Lippitz, J. F.Friedrich, W. E. S. Unger. Study of influence of external plasma parameters on plasma polymerised films prepared from organic molecules (acrylic acid, allyl alcohol, allyl amine) using XPS and NEXAFS. Surf. Coat. Technol. 200 (2005) 494-497. https://doi.org/10.1016/j.surfcoat.2005.01.083.

[28] Labbaye, T.; Canizarès, A.; Gaillard, M.; Lecas, T.; Kovacevic, E.; Boulmer-Leborgne, Ch.; Strunskus, T.; Raimboux, N.; Simon, P.; Guimbretière, G.; Ammar, M. R. In situ Raman spectroscopy for growth monitoring of vertically aligned multiwall carbon nanotubes in plasma reactor. Appl. Phys. Lett. 2014, 105, 213109. https://doi.org/10.1063/1.4902915.

[29] Stöhr, J.; NEXAFS Spectroscopy, Springer Series in Surface Sciences 1992 [30] D. Debarnot, T. Mérian, F. Poncin-Epaillard, Effect of fluorine substitution of aniline ring on pulsed plasma polymer growth and Structure. Plasma Proc. Polym. 8 (2011) 763-772. https://doi.org/10.1002/ppap.201000204.

[31] D. Debarnot, T. Mérian, F. Poncin-Epaillard. Film chemistry control and growth kinetics of pulsed plasma-polymerized aniline. Plasma Chem. Plasma Proc. 31 (2011) 217-231. https://doi.org/10.1007/s11090-010-9271-2.

[32] T. H. Tran, D. Debarnot, J. Ortiz, F., Poncin-Epaillard, Plasma codeposition of transparent thin film: relationship between surface chemistry and anti-fogging property. Plasma Proc. Polym. 16 (2019) e1900070. https://doi.org/10.1002/ppap.201900070.

[33] L. Carrino, G. Moroni, W. Polini. Cold plasma treatment of polypropylene surface: A study on wettability and adhesion. J. Mater. Process. Technol. 121 (2002) 373-382. https://doi.org/10.1016/S0924-0136(01)01221-3. 
[34] C. Chahine, F. Poncin-Epaillard, D. Debarnot, Plasma Copolymerization of fluorinated and acrylate monomers: kinetics and chemical Structure Study. Plasma Process. Polym. 12 (2015) 493501. https://doi.org/10.1002/ppap.201400128.

[35] S. Morita, A. T. Bell, M. Shen. The effect of frequency on the plasma polymerization of ethane. J. Polym. Sci. Polym. Chem. Ed. 17 (1979) 2775-2782. https://doi.org/10.1002/pol.1979.170170914.

[36] A. Airoudj, G. Schrodj, M.-F. Vallat, P. Fioux, V. Roucoules, Influence of Plasma Duty Cycle during Plasma Polymerization in Adhesive Bonding. Int. J. Adhes. Adhes. 31(2011) 498-506. https://doi.org/10.1016/j.ijadhadh.2011.05.003.

[37] L. P. Yeo, Y. H. Yan, Y. C. Lam, M. B. Chan-Park, Design of experiment for optimization of plasma-polymerized octafluorocyclobutane coating on very high aspect ratio silicon molds. Langmuir 22 (2006) 10196-10203. https://doi.org/10.1021/la061334q.

[38] A. Solouk, M. Solati-Hashjin, S. Najarian, H. Mirzadeh, A.M. Seifalian, Optimization of acrylic acid grafting onto POSS-PCU nanocomposite using response surface methodology. Iran. Polym. J. 20 (2011) 91-107.

[39] Siffer, F.; Ponche, A.; Fioux, P.; Schultz, J.; Roucoules, V. A. Chemometric investigation of the effect of the process parameters during maleic anhydride pulsed plasma polymerization. Anal. Chim. Acta 2005, 539, 289-299. https://doi.org/10.1016/j.aca.2005.02.072.

[40] Ruiz, J. C.; Girard-Lauriault, P. L.; Wertheimer, M. R. Fabrication, characterization, and comparison of oxygen-rich organic films deposited by plasma- and vacuum-ultraviolet (VUV) photo-polymerization, Plasma process. polym. 2015, 12, 225-236 https://doiorg/10.1002/ppap.201400146.

[41] H. Biederman, Plasma polymer films. World scientific edition. 2004 https://doi.org/10.1142/p336.

[42] I. Retzko, J. F. Friedrich, A. Lippitz, W. E. S.Unger, Chemical analysis of plasma-polymerized films: the application of X-Ray photoelectron spectroscopy (XPS), X-Ray absorption spectroscopy (NEXAFS) and fourier transform infrared spectroscopy (FTIR). J. Electron Spectrosc. Relat. Phenom. 121 (2001) 111-129. https://doi.org/10.1016/S0368-2048(01)00330-9.

[43] A. M. de Oliveira Neto, W. H. Schreiner, J. F. Justo, A. M. de Oliveira, E. C. Rangel, S. F. Durrant. Characterization of amorphous carbon films by PECVD and plasma ion implantation: the role of fluorine and sulfur doping. Mater. Chem. Phys. 227 (2019) 170-175. https://doi.org/10.1016/j.matchemphys.2019.02.008.

[44] E. Kasparek, J. R. Tavares, M. R. Wertheimer, P-L. Girard-Lauriault ,VUV photodeposition of thiol-terminated films: a wavelength-dependent study. Langmuir 34 (2018) 12234-12243 https://doi.org/10.1021/acs.langmuir.8b01691

[45] C. G. Spanos, J. P. S. Badyal, A. J. Goodwin, P. J. Merlin. Pulsed plasmachemical deposition of polymeric salt networks. Polymer 46 (2005) 8908-8912. https://doi.org/10.1016/j.polymer.2005.06.123.

[46] J. Friedrich, R. Mix, G. Kühn, I. Retzko, A. Schönhals, W. Unger. Plasma-based introduction of monosort functional groups of different type and density onto polymer surfaces. Part 2: Pulsed plasma polymerization. Compos. Interfaces $10 \quad$ (2003) 173-223. https://doi.org/10.1163/156855403765826874.

[47] G. Le Dû, N. Celini, F. Bergaya, F. Poncin-Epaillard. Rf Plasma-Polymerization of Acetylene: Correlation between plasma diagnostics and deposit characteristics. Surf. Coat. Technol. 201, (2007) 5815-5821. https://doi.org/10.1016/j.surfcoat.2006.10.025. 
[48] A. Fahmy, T. A. Mohamed, A. Schönhals. Structure of plasma poly(acrylic acid): influence of pressure and dielectric properties. Plasma Chem Plasma Process 35 (2015) 303-320. https://doi.org/10.1007/s11090-014-9603-8.

[49] G. Beamson, D. Briggs. High resolution XPS of organic polymers: The Scienta ESCA300 database Wiley, 1992.

[50] F. Palumbo, P. Favia, A. Rinaldi, M. Vulpio, R. d'Agostino, PE-CVD of organic thin films with controlled surface concentration of carboxylic groups. Plasmas Polym. 4 (1999) 133-145. https://doi.org/10.1023/A:1021896808872.

[51] J. Hu, C. Yin, H.-Q. Mao, K. Tamada, W. Knoll. Functionalization of poly(ethylene terephthalate) film by pulsed plasma deposition of maleic anhydride. Adv. Funct. Mater. 13 (2003) 692-697. https://doi.org/10.1002/adfm.200304384.

[52] U. Rittihong, H. Akasaka, C. Euaruksakul, M. Tomidokoro, N. Kamonsuttipaijit, H. Nakajima, R. Supruangnet, C. Rojviriya, A. Chingsungnoen, P. Poolcharuansin, N. Ohtake, S. Tunmee. Synchrotron-based spectroscopic analysis of diamond-like carbon films from different source gases. Rad. Phys. Chem. 173 (2020) 108944 https://doi.org/10.1016/j.radphyschem.2020.108944. [53] F. Bournel, C. Laffon, Ph. Parent, G. Tourillon. Adsorption of acrylic acid on aluminum at 300 K: A multi-spectroscopic study. Surf. Sci. 352-354 (1996) 228-231. https://doi.org/10.1016/0039-6028(95)01138-2.

[54] S. Swaraj, U. Oran, A. Lippitz, J. F. Friedrich, W. E. S. Unger, Study of influence of external plasma parameters on plasma polymerised films prepared from organic molecules (Acrylic acid, allyl alcohol, allyl amine) using XPS and NEXAFS. Surf. Coat. Technol. 200 (2005) 494-497. https://doi.org/10.1016/j.surfcoat.2005.01.083.

[55] A. Lopez, T. Bitzer, T. Heller, N. V. Richardson. Adsorption of maleic anhydride on Si(100)2×1. Surf. Sci. 477 (2001) 219-226. https://doi.org/10.1016/S0039-6028(01)00775-0.

[56] S. Gil Girol, T. Strunskus, M. Muhler, C. Wöll, Reactivity of ZnO surfaces toward maleic anhydride. J. Phys. Chem. B 108 (2004) 13736-13745. https://doi.org/10.1021/jp048386d.

[57] M. Samadi, A. Eshaghi, S. R. Bakhshi, A. A. Aghaei. The influence of gas flow rate on the structural, mechanical, optical and wettability of diamond-like carbon thin films. Opt. Quantum Electron. 50 (2018) 193. https://doi.org/10.1007/s11082-018-1456-6.

[58] A. Liguori, A. Owens, A. Stancampiano, F. Tarterini, M. L. Focarete, V. Colombo, M. Gherardi. Deposition of plasma-polymerized polyacrylic acid coatings by a non-equilibrium atmospheric pressure nanopulsed plasma jet. Plasma Process. Polym. 13 (2016) 375-386. https://doi.org/10.1002/ppap.201500080.

[59] D. K. Owens, R. C. Wendt. Estimation of the surface free energy of polymers. J. Appl. Polym. Sci., 13 (1969) 1741-1747. https://doi.org/10.1002/app.1969.070130815.

[60] A. Zaitsev, F. Poncin-Epaillard, A. Lacoste, D. Debarnot. A bottom-up and templateless process for the elaboration of plasma-polymer nanostructures. Plasma Proc. Polym. 13 (2016) 227235. https://doi 10.1002/ppap.201500014. 